\title{
Evaluation of the plane of array irradiance for a photovoltaic installation equipped with flat reflectors in different geographical locations
}

\author{
Christine Abdel Nour ${ }^{\mathrm{a}, \mathrm{b}, \mathrm{d}}$, Anne Migan-Dubois ${ }^{\mathrm{a}}$, Jordi Badosa ${ }^{\mathrm{b}}$, Vincent Bourdin ${ }^{\mathrm{c}}$, Claude Marchand ${ }^{\mathrm{a}}$, Tilda \\ Akiki $^{\mathrm{d}}$ \\ ${ }^{a}$ GeePs ; CNRS UMR 8507 ; CentraleSupélec ; Univ Paris-Sud ; Sorbonne Université ; 11 rue Joliot-Curie, \\ Plateau de Moulon, F-91192 Gif-sur-Yvette Cedex, France \\ ${ }^{\mathrm{b}}$ LMD, Institut Pierre-Simon Laplace, CNRS, École Polytechnique, 91128 Palaiseau Cedex, France \\ ${ }^{c}$ LIMSI, UPR 3251 CNRS, Bâtiment 508, Rue John von Neumann, 91405 Orsay Cedex France \\ ${ }^{\mathrm{d}}$ Holy Spirit University of Kaslik, USEK, Electrical Engineering Department, BP446 Jounieh, Lebanon
}

\begin{abstract}
This work describes a plane of array irradiance (GPOA) estimation study performed for a PV system equipped with flat reflectors. In fact, adding planar reflectors in front of the PV arrays will result in an increased GPOA reaching the panel's surface. This paper focuses on the GPOA study for a PV-Reflector system architecture in six different geographical locations. The study was conducted over a five years period of time and under various weather conditions. An analytical model was developed and experimentally validated for that purpose allowing the estimation and assessment of the GPOA for such system. Therefore, the study was performed according to an architectural optimization approach considering several geometrical variations in order to achieve the highest plane of array irradiance. The highest annual gain in GPOA added by the reflectors was obtained for Athens (35\%) and regions with close latitudes showed quite similar results.
\end{abstract}

Index Terms - Geometrical optimization, photovoltaic systems, plane of array irradiance, PV-Reflector architecture.

\section{INTRODUCTION}

Within the climate change awareness nowadays, the renewable energies growth is accelerating significantly. For instance, photovoltaic energy sector is developing exponentially. The estimation of the irradiance incident on the PV modules plane occupies a high importance when studying a photovoltaic installation power generation. Several technologies were developed in order to increase the concentration of the irradiance flux on the PV modules in order to enhance the electrical power generation. We can cite parabolic sensor systems [1] and Fresnel reflector systems [2]. Nevertheless, these two technologies are not viable in areas with low direct irradiance and their manufacturing cost is considerably high. In addition, CPV technology based on curved lenses allowing the concentration of irradiance on small multi-junction solar cells allow high efficiency levels [3]. However the latter technology requires a cooling system and accurate solar trackers which increases the complexity and cost of the system as well. Therefore, planar reflectors technology allowing the increase of the incident flux on a PV module with a low cost comparable to that of previous technologies at manufacturing and complexity levels comes as a promising solution and several studies are under development in order to evaluate its efficiency [4] [5]. The irradiance in the plane of array (GPOA) assessment is an approach requiring calculations based on several parameters and measurements and it becomes more complex when adding planar reflectors in front of the panels. Several optical, geometrical and solar data must be taken into account for that purpose. On the other hand, the plane of array irradiance of a PV-Reflector system will be highly affected by the longitude, latitude and weather conditions. In this work, six different locations will be studied in this paper: Athens, Oslo, Palaiseau, New Delhi, Ouarzazat and Chicago (Table I). The irradiance data ( horizontal beam and diffuse) were taken from PVGIS (Photovoltaic Geographical Information System) dataset over a five years period (2012-2016) providing geographical assessment of solar resource and performance of photovoltaic technology [6] [7].

TABLE I

DIFFERENT LOCATIONS STUDIED

\begin{tabular}{|c|c|c|c|c|}
\hline Country & Location & Latitude & Longitude & $\begin{array}{c}\text { Diffuse } \\
\text { ratio }\end{array}$ \\
\hline Norway & Oslo & 59.9 & 10.73 & 0.49 \\
\hline France & Palaiseau & 48.71 & 2.24 & 0.53 \\
\hline USA & Chicago & 41.87 & -87.62 & 0.39 \\
\hline Greece & Athens & 37.98 & 23.72 & 0.26 \\
\hline Morocco & Ouarzazat & 30.92 & -6.91 & 0.28 \\
\hline India & New Delhi & 28.61 & 77.2 & 0.42 \\
\hline
\end{tabular}




\section{Methodology}

\section{A. Analytical estimation model}

The analytical model input parameters used in our calculations are:

- The latitude and longitude of each location (decimal degrees).

- BHI: The beam horizontal irradiance $\left(\mathrm{W} / \mathrm{m}^{2}\right)$, from which the beam normal irradiance (BNI) is calculated.

- DHI: The diffuse horizontal irradiance $\left(\mathrm{W} / \mathrm{m}^{2}\right)$.

- OSunEl: The solar elevation angle $\left(^{\circ}\right)$.

- Albedo: The ground reflectivity factor.

- The mirror's reflectivity factor.

- Lr: The planar reflector Length (m).

- Lpv: The photovoltaic panel length (m).

- Otilt: The inclination angle of the PV module to the horizontal plane $\left(^{\circ}\right)$.

- $\quad$ OR: The angle between reflector and the horizontal plane $\left(^{\circ}\right)$.

The analytical model allows the calculation of the sun profile and position (Azimuth and Zenith) [8], the global horizontal irradiance (GHI), the angle of incidence (AOI ) and the view factor (between PV module and reflectors) to finally compute the plane of array irradiance in both cases: presence $\left(\mathrm{GPOA}_{\mathrm{Mir}}\right)$ (1) and absence (GPOA) (2) of reflectors. The detailed model and equations as well as the experimental validation were developed in a previous work [9]. In order to validate our model, experimental GPOA measurements were performed over one year, without mirror with $\Theta$ tilt $=27^{\circ}$ as well as for a period with mirrors $\left(\Theta R=15^{\circ}\right)$ at SIRTA observatory [10], a reference meteorological and climate observatory in Palaiseau (France) which is part of BSRN (see details in [9]).

The following equations summarize the calculation of GPOA without and with reflectors, respectively [11]:

$$
\begin{array}{r}
\text { GPOA }=\left(\frac{G H I-D H I}{\sin (\text { O SunEl })}\right) \times \cos (A O I)+D H I \times \frac{1+\cos (\text { Otilt }(\mathrm{pv}))}{2} \\
+ \text { GHI } \times \text { Albedo } \times \frac{1-\cos (\text { Otilt }(\mathrm{pv}))}{2} \\
\text { GPOA }_{\text {Mir }}=\frac{\mathrm{GHI}-\mathrm{DHI}}{\sin (\text { O SunEl })} \times \cos (\mathrm{AOI})+\mathrm{DHI} \times \frac{1+\cos (\text { Otilt }(\mathrm{pv}))}{2} \\
+ \text { GHI } \times \text { Albedo } \times\left(\frac{1-\cos (\text { Otilt }(\mathrm{pv}))}{2}-\mathrm{VF}_{\mathrm{PV}_{\mathrm{R}}}\right)+\text { DRBI }+ \text { DRSR }
\end{array}
$$

With DRBI and DRSR represent the direct and diffuse radiations reaching the reflector to be then absorbed by the PV array (see the details in [4] and [9]). The DRBI contribution was only considered if the reflected irradiance covered the whole Lpv length. The case in which the Sun would be behind the reflector was also considered, for which GPOA $_{\text {Mir }}$ would only have a diffuse irradiance contribution
[9]. Both equations 1 and 2 assume that the sky diffuse radiation is isotropic and the ground reflected radiation is Lambertian.

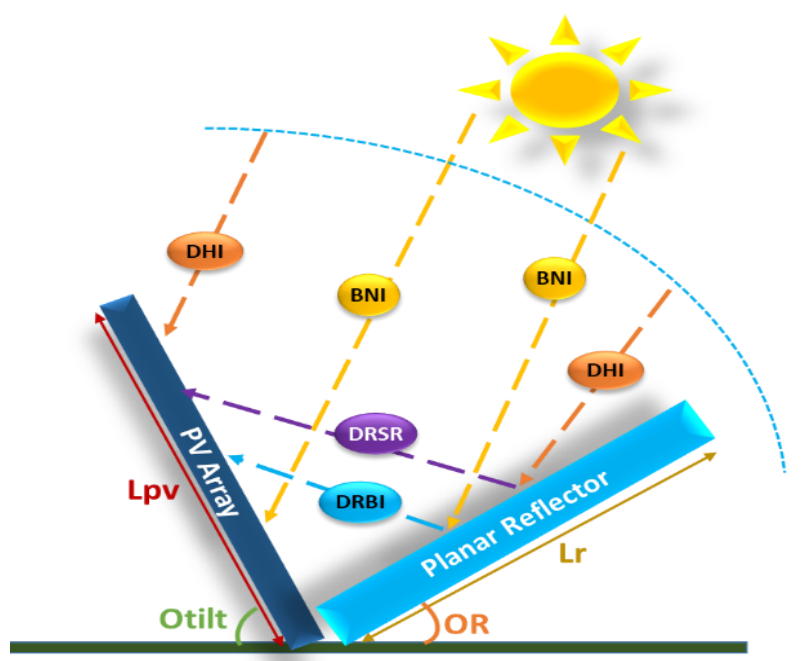

Fig. 1. PV-Reflector system architecture

\section{B. Optimization strategy}

The objective was to find the optimal parametrical combination (Өtilt, $\Theta R$ ) from which the maximum average gain in GPOA (added by the mirrors) was computed. For this, the following variations were considered :

- Three possibilities for the reflector's length ( $\mathrm{Lr})$ were considered according to the lenght of the PV panel (Lpv): Lpv/2, Lpv and 2Lpv.

- Three architectural possibilities, affecting Otilt and OR: a fixed configuration, a seasonal adjustment and a monthly adjustment.

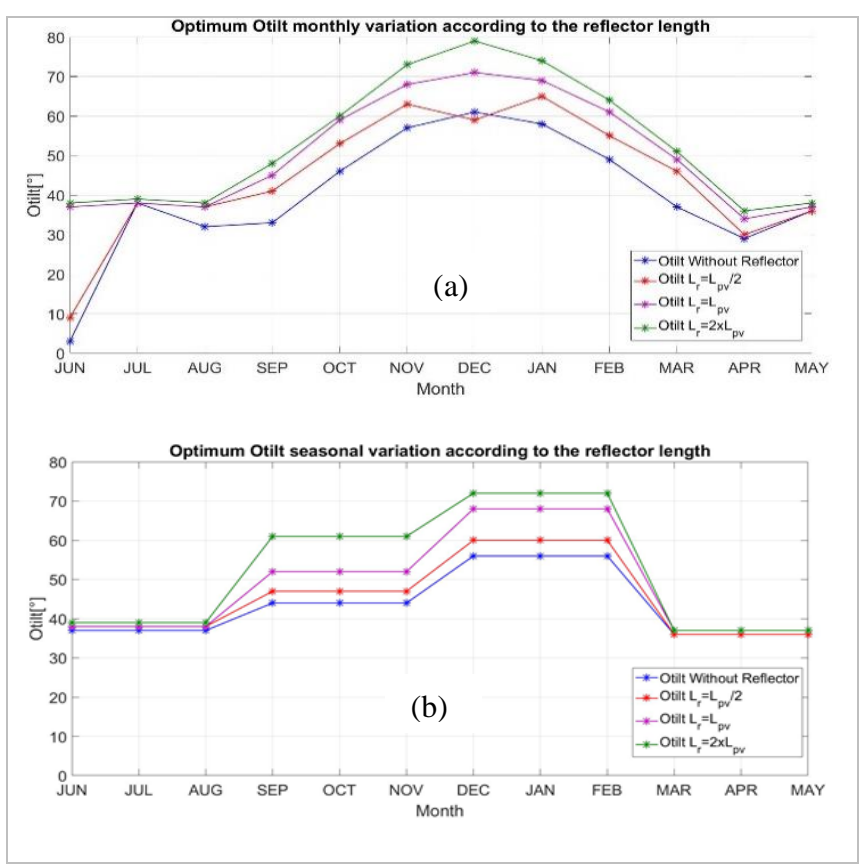




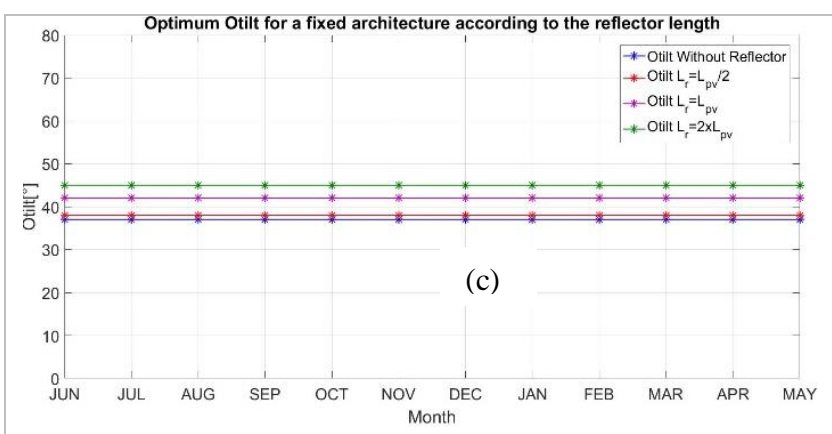

Fig. 2. Optimum Otilt for Athens according to the reflector's length for monthly varied (a) seasonal varied (b) and fixed architectures (c)
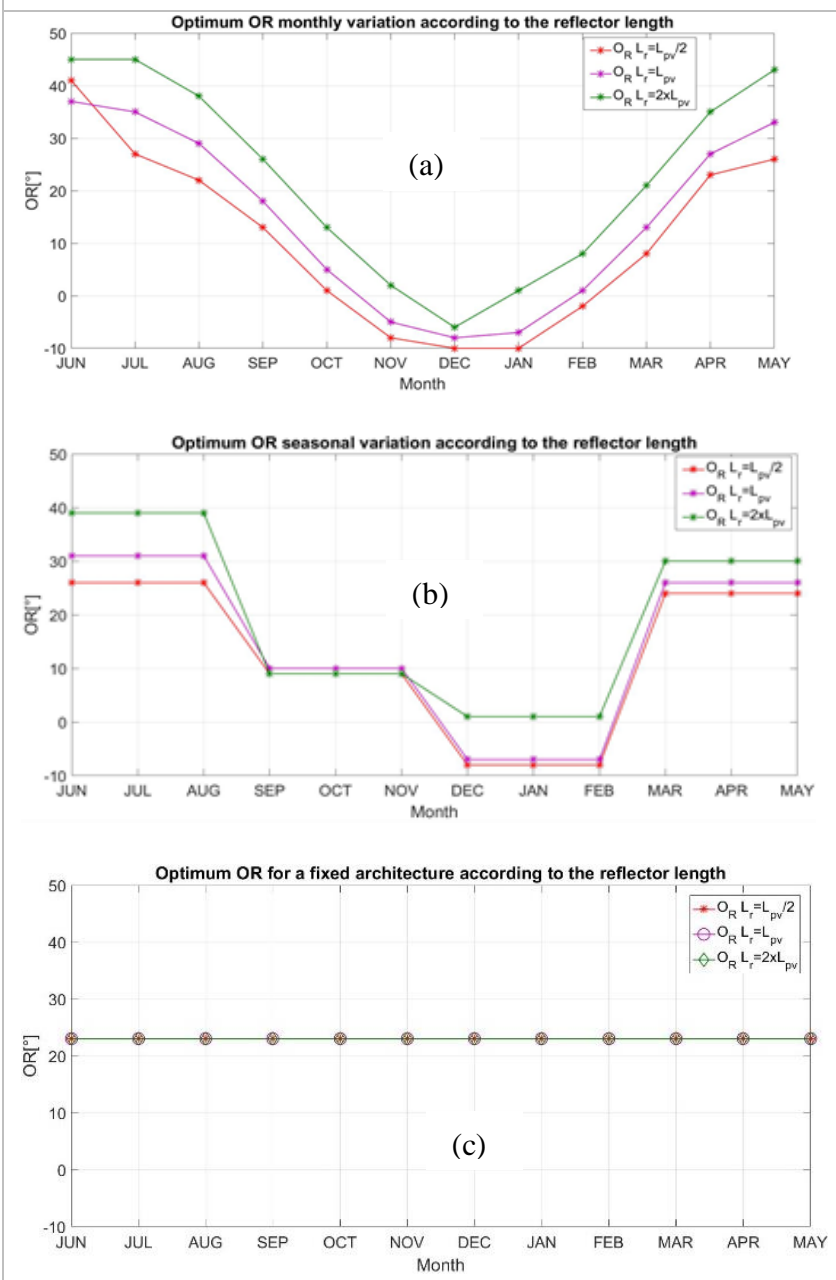

Fig. 3. Optimum $\Theta R$ for Athens according to the reflector's length for monthly varied (a) seasonal varied (b) and fixed architectures (c)

Figures 2 and 3 illustrate the optimal $\Theta$ tilt and $\Theta R$ angles combinations obtained for Athens: average result of each 5 same months over the period considered ( 5 years), and considering a monthly (Fig. 2a and 3a) a seasonal (Fig. 2b and $3 \mathrm{~b}$ ) variation of the angles or a fixed architecture (Fig.
$2 \mathrm{c}$ and $3 \mathrm{c})$. Each figure shows the results for each reflector's length $(\mathrm{Lr}=\mathrm{Lpv} / 2, \mathrm{Lr}=\mathrm{Lpv}$ and $\mathrm{Lr}=2 \mathrm{Lpv})$. Fig. 2 and 3 show that in winter, it is more efficient to straighten the PV array since the sun is lower. It is the opposite case during summer. Otilt and $\Theta R$ vary in opposite cycles. Regarding the reflector, it's seen that for the lowest length (Lpv/2), the optimum results are obtained for lower $\mathrm{OR}$ values compared to Lpv and 2Lpv. In an optical perspective, for small mirror's length, it's important to lower it in order to allow its reflected irradiance to reach the top of the PV panel and thus avoid non uniform irradiance resulting in critical losses on the power production level. On the other hand, when increasing the mirror's length exceeding the length of the PV panel, it becomes interesting to straighten the reflector ( $(\mathrm{R})$ as well as the PV module (Otilt) in order to avoid losing a part of the reflected irradiance that could outreach the module's height.
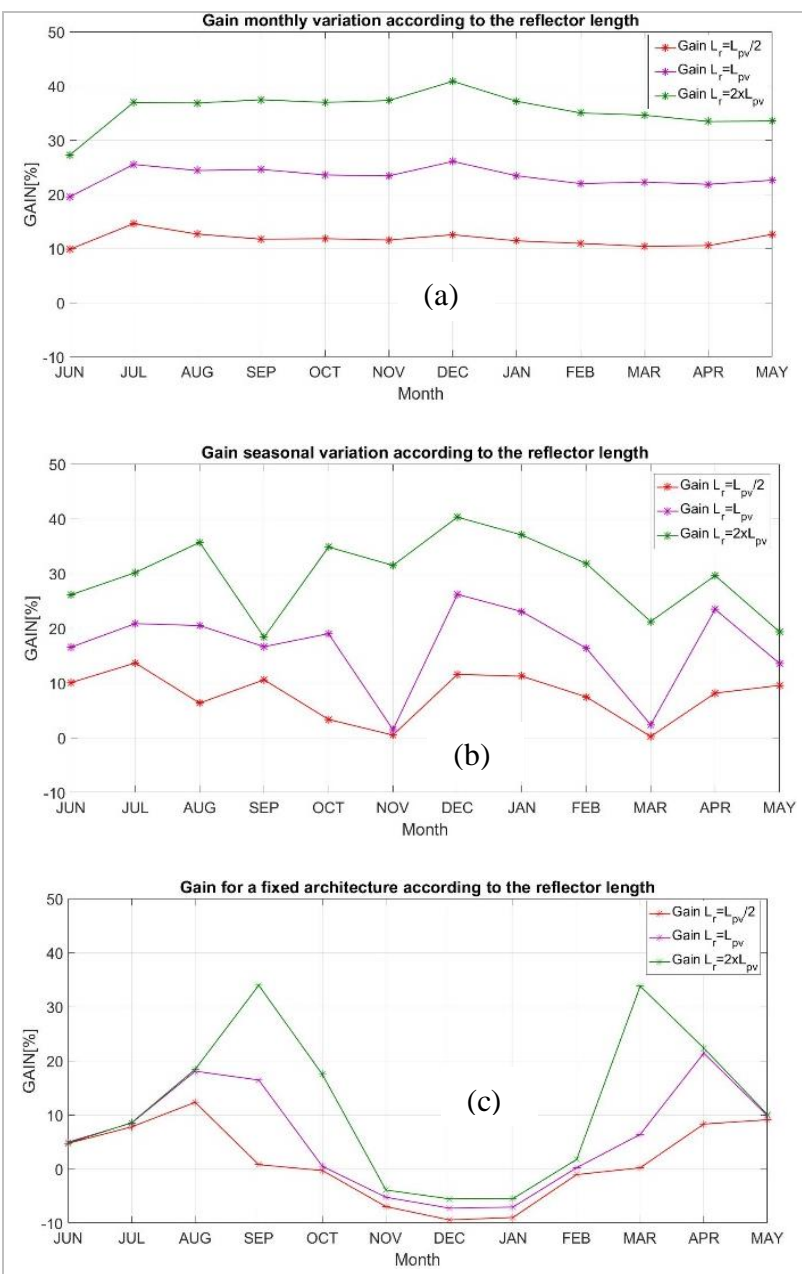

Fig. 4. Gain in GPOA for Athens according to the reflector's length for monthly varied (a) seasonal varied (b) and fixed architectures (c)

Once the optimal geometrical configurations are retrieved out of the optimization process, the gain in GPOA 
added by the mirrors is calculated for each month as well as for the entire period as follows:

Gain in GPOA added by the reflectors over each month:

$G_{M}=1-\frac{\sum G P O A_{\text {mir,month }}\left(\theta \text { tilt }_{\text {mir,optimum }}, \theta R_{\text {optimum }}\right)}{\sum G P O A_{\text {month }}\left(\theta \text { tilt }_{\text {optimum }}\right)} \times 100$

Gain in GPOA added by the reflectors over the entire period (5 years):

$G_{A}=1-\frac{\sum G P O A_{\text {mir }}\left(\theta \text { tilt }_{\text {mir,optimum }}, \theta R_{\text {optimum }}\right)}{\sum G P O A\left(\text { tilt }_{\text {optimum }}\right)}$ $\times 100$

With:

- $G P O A$ and GPOA mir given by equations 1 and 2 , respectively.

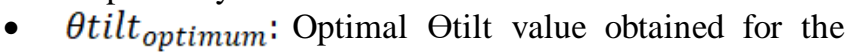
architecture without mirrors.

- $\quad$ tilt $_{\text {mir,optimum }}$ : Optimal Otilt value obtained for the architecture with mirrors.

- $\theta R_{\text {optimum }}$ : Optimal $\Theta \mathrm{R}$ value obtained.

Figure 4 illustrates the gain obtained for each month after the optimization process for monthly varied (Fig. 4a), seasonal varied (Fig. 4b) and fixed (Fig. 4c) architectures. For monthly variation, through the gain curve we can observe that the geometrical optimization satisfies (gives a positive gain) each month. With seasonal variation, some months are penalized through the geometrical optimization compared to the monthly variation, nevertheless, the gains stay positive for all reflector's lengths. However, for fixed architecture, some months are highly affected with negative gain. This phenomenon can be observed between November and February and it is due to a shading effect of the reflectors onto the PV plane when the Sun is low. In this way, for this months, it would be better to remove the reflector or lower it to the horizontal plane $(\Theta \mathrm{R}=0)$ in order to avoid its shading effect and therefore avoid PV power production losses. Finally, with a high reflector's length the higher gains achieved for fixed architectures are around spring and autumn equinoxes (around March and September) as illustrated in figure $4 \mathrm{c}$. The same process was repeated for all locations and the optimization results were retrieved.

\section{RESULTS AND DISCUSSIONS}

The same architectural optimization strategy was conducted for all the geographical locations (Table I). Table II presents the optimal average gain in GPOA results added by the reflectors calculated over a five years period. Monthly and seasonal varied as well as fixed architectures were considered with different reflector's length.
TABLE II

GAIN FOR THE OPTIMIZED ARCHITECTURES OBTAINED FOR THE ENTIRE STUDIES PERIOD (2012-2016)

\begin{tabular}{|c|c|c|c|c|}
\hline & & $\begin{array}{l}\text { Monthly } \\
\text { variation }\end{array}$ & $\begin{array}{l}\text { Seasonal } \\
\text { variation } \\
\end{array}$ & $\begin{array}{c}\text { Fixed } \\
\text { architecture }\end{array}$ \\
\hline Location & $\begin{array}{c}\text { Reflector's } \\
\text { Length }\end{array}$ & \multicolumn{3}{|c|}{ Gain (\%) } \\
\hline \multirow{3}{*}{ Oslo } & $\overline{\mathrm{Lr}}=\mathrm{Lpv} / 2$ & 7.7 & 5.1 & 3.3 \\
\hline & $\mathrm{Lr}=\mathrm{Lpv}$ & 17.6 & 12.2 & 8.2 \\
\hline & $\mathrm{Lr}=2 * \mathrm{Lpv}$ & 32.0 & 24.3 & 16.1 \\
\hline \multirow{3}{*}{ Palaiseau } & $\mathrm{Lr}=\mathrm{Lpv} / 2$ & 7.9 & 5.3 & 2.6 \\
\hline & $\mathrm{Lr}=\mathrm{Lpv}$ & 17.1 & 12.0 & 6.9 \\
\hline & $\mathrm{Lr}=2 * \mathrm{Lpv}$ & 28.1 & 21.7 & 12.6 \\
\hline \multirow{3}{*}{ Chicago } & $\mathrm{Lr}=\mathrm{Lpv} / 2$ & 9.9 & 6.1 & 2.0 \\
\hline & $\mathrm{Lr}=\mathrm{Lpv}$ & 20.1 & 13.7 & 6.5 \\
\hline & $\mathrm{Lr}=2 * \mathrm{Lpv}$ & 31.7 & 25.1 & 12.4 \\
\hline \multirow{3}{*}{ Athens } & $\mathrm{Lr}=\mathrm{Lpv} / 2$ & 11.8 & 7.9 & 2.5 \\
\hline & $\mathrm{Lr}=\mathrm{Lpv}$ & 23.2 & 16.7 & 6.9 \\
\hline & $\mathrm{Lr}=2 * \mathrm{Lpv}$ & 35.4 & 29.2 & 12.7 \\
\hline \multirow{3}{*}{ Ouarzazat } & $\mathrm{Lr}=\mathrm{Lpv} / 2$ & 10.8 & 6.6 & 2.7 \\
\hline & $\mathrm{Lr}=\mathrm{Lpv}$ & 20.6 & 15.0 & 6.7 \\
\hline & $\mathrm{Lr}=2 * \mathrm{Lpv}$ & 30.5 & 26.3 & 13.9 \\
\hline \multirow{3}{*}{$\begin{array}{l}\text { New } \\
\text { Delhi }\end{array}$} & $\mathrm{Lr}=\mathrm{Lpv} / 2$ & 9.1 & 6.0 & 2.8 \\
\hline & $\mathrm{Lr}=\mathrm{Lpv}$ & 17.5 & 13.1 & 6.9 \\
\hline & $\mathrm{Lr}=2 * \mathrm{Lpv}$ & 26.7 & 23.2 & 14.9 \\
\hline
\end{tabular}

Table II presents the Gain in GPOA added by the reflectors over the entire period (5 years). This gain was obtained by computing the added GPOA in a PV-reflector system compared to a classical PV system (without reflector). Lowest gain is found for small reflectors and fixed architecture configuration (annual gain range from 2.0 to $3.3 \%$ for $\mathrm{Lr}=\mathrm{Lpv} / 2$ ). GPOA gain doubles from $\mathrm{Lr}=\mathrm{Lpv} / 2$ to $\mathrm{Lr}=\mathrm{Lpv}$ for monthly and seasonal varied architectures and triples for the fixed one. It's not the same behavior between $\mathrm{Lr}=\mathrm{Lpv}$ and $\mathrm{Lr}=2 \mathrm{Lpv}$ where the gain increasing ratio is lower. In fact, the larger we extend the length of the mirrors beyond $\mathrm{Lr}=\mathrm{Lpv}$, the shading effect increases.

Figures 5 and 6 compare the average gain according to the reflector's length in the different geographical locations studied through this work. $\mathrm{Lr}=2 * \mathrm{Lpv}$ and the monthly variation were taken as references in Fig. 5 and Fig. 6 respectively, thus all other scenarios were normalized and represented according to these references. 


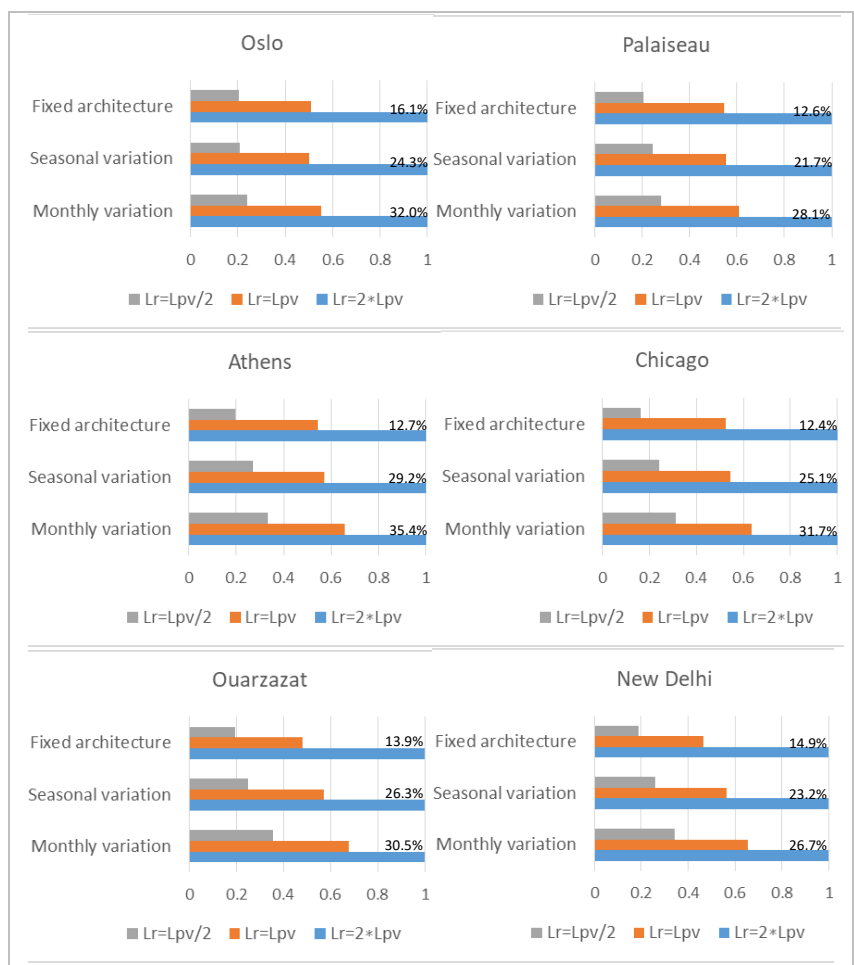

Fig. 5. Gain comparison according to the reflector's length

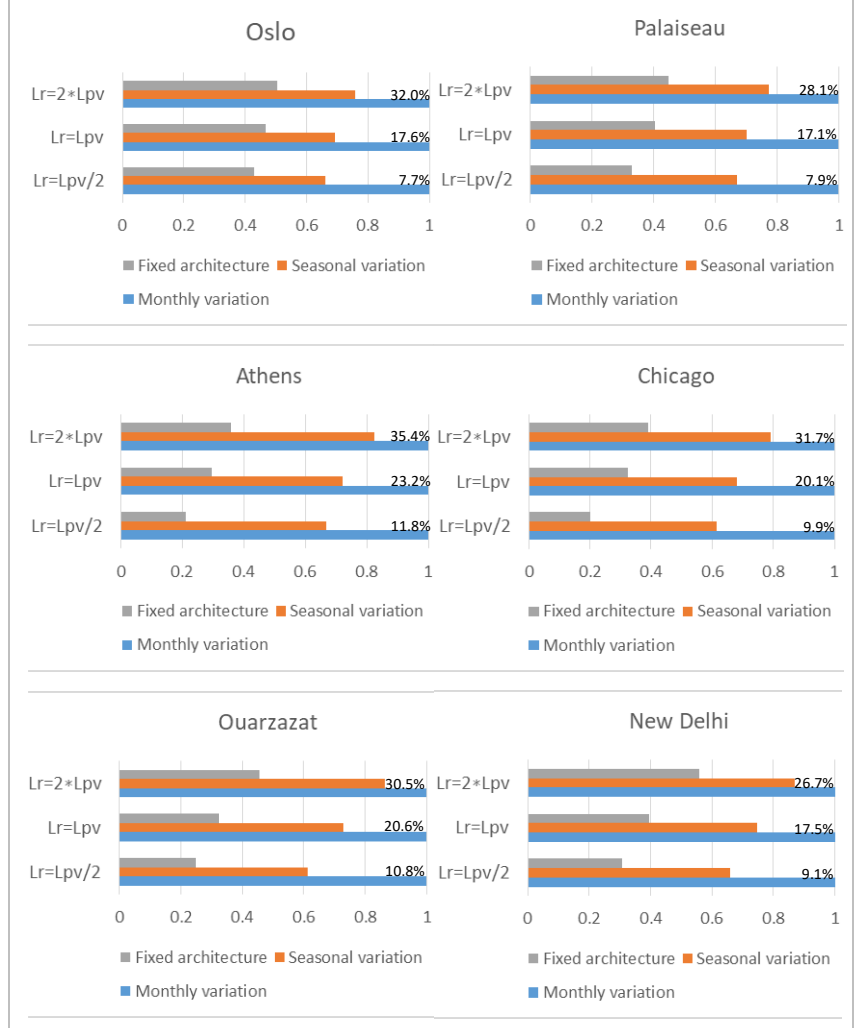

Fig. 6. Gain comparison according to the angular variation

From the previous results (Fig.4 and Table II), we can notice the effect of the reflector's length as well as the angular variation on the computed gain. Almost the same behavior is observed for all regions (Fig. 5); increasing the length of the mirrors will increase the gain. Nevertheless, the gain sensibility in reflector's length increases for fixed architectures. Fig. 6 shows that limiting Lr to Lpv/2 in a fixed architecture will significantly decrease the plane of array irradiance reaching the PV panel. In the latter case, going from $\mathrm{Lr}=\mathrm{Lpv} / 2$ to $\mathrm{Lr}=\mathrm{Lpv}$ will triple the gain. On the other hand, going from $\mathrm{Lr}=\mathrm{Lpv}$ to $\mathrm{Lr}=2 * \mathrm{Lpv}$ will double the gain for the fixed architecture because of the shading effect described previously. Fig. 6 shows that limiting Otilt and $\Theta R$ to a fixed architecture will significantly decrease GPOA especially for $\mathrm{Lr}=\mathrm{Lpv} / 2$. Nevertheless, in the latter case Athens and Chicago are the most affected where we can clearly notice the drop of the gain by $80 \%$ going from monthly variation to a fixed architecture. However, for high reflector's length $(\mathrm{Lr}=2 * \mathrm{Lpv})$ we have a drop ratio between 10 and $25 \%$ going from monthly to seasonal varied architectures for all regions. Therefore, the more $\mathrm{Lr}$ is high the more a monthly varied architecture is less advantageous compared to the seasonal varied one. The results for Ouarzazat and New Delhi cities were quite similar since they have close latitudes, the same observation can be noticed for Athens and Chicago having close latitudes as well. evertheless, according to the results presented in Table II, the GPOA gain in Ouarzazat and Athens exceeds that of New Delhi and Chicago respectively and that can be explained by the diffuse ratio around 0.28 in Ouarzazat compared to 0.42 in New Delhi and 0.26 in Athens compared to 0.39 in Chicago. Thus, the average direct irradiance is higher in Ouarzazat and Athens highlighted by slightly higher gains than the regions of their same latitudes. Finally, an interesting observation can be noticed for Oslo with the highest gain ratios for fixed architecture. In this location with high latitude, the sun reaches the lowest levels which introduces the advantage of lowering the mirrors in all optimization processes in order to avoid shading effects.

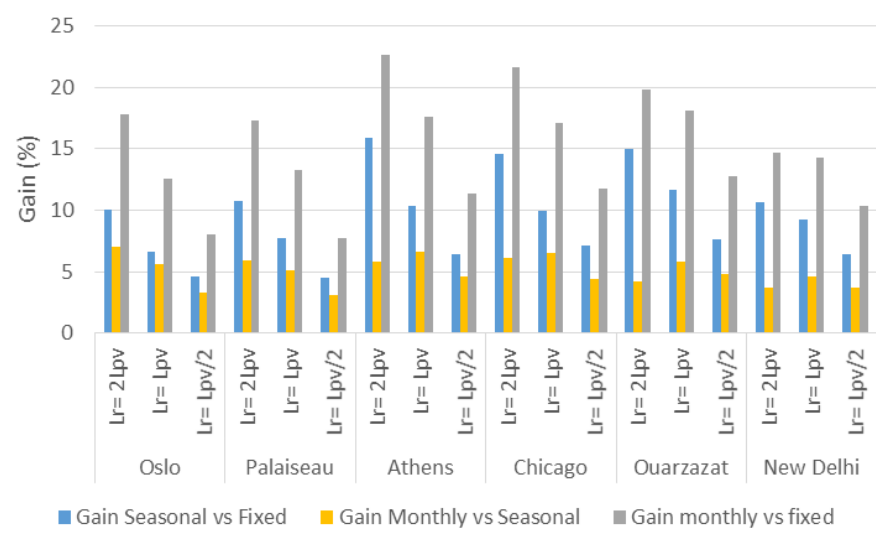

Fig. 7. Gain comparison between PV-Reflector architectures according to angular variation frequency 
Figure 7 describes the gain ratios obtained comparing the GPOA between PV-reflector architectures: a seasonal varied architecture to a fixed one, a monthly varied to a seasonal varied and finally a monthly varied to a fixed architecture. We can observe that for all locations, the gain in GPOA comparing monthly varied to fixed is the highest and it increases by increasing the reflector's length. Gain seasonal vs fixed shows that the highest is $\mathrm{Lr}$, the more significant is to choose the seasonal varied architecture.

\section{CONCLUSION}

A GPOA estimation modelling for a photovoltaic installation equipped with planar reflectors was presented through this work. The architectural optimization study of such system was conducted for six different regions with different latitudes and meteorological conditions over a period of five years from 2012 to 2016. The optimization results showed that each region requires specific considerations.

GPOA gain doubles or triples from $\mathrm{Lr}=\mathrm{Lpv} / 2$ to $\mathrm{Lr}=\mathrm{Lpv}$ in monthly and seasonal variations. The gain does not increase similarly going from $\mathrm{Lr}=\mathrm{Lpv}$ to $\mathrm{Lr}=2 \mathrm{Lpv}$ where the increasing ratio is lower. In fact, the larger we extend the length of the mirrors beyond $\mathrm{Lr}=\mathrm{Lpv}$, the mirrors shading effect increases. Regions with close latitudes like Ouarzazat and New Delhi showed quite similar results in terms of geometrical optimization and gain in GPOA the same fact was observed between Athens and Chicago having close latitudes as well. The highest gain was achieved was $35 \%$ considering a monthly varied architecture with $\mathrm{Lr}=2 * \mathrm{Lpv}$ in Athens where Oslo presented the highest gains in fixed architectures because of its geographical location. A fixed architecture with small reflectors ( $\mathrm{Lr}<=\mathrm{Lpv}$ ) show low interest as the gain is $8.2 \%$ at the most (in Oslo). The described optimization process with smaller time step is under development and will be published in a future work. Finally, a power production average gain assessment will be conducted using the GPOA results obtained as well a MPPT model developed in a previous work [12].

\section{ACKNOWLEDGEMENTS}

This work was supported by the TREND-X research program of Ecole Polytechnique.

\section{REFERENCES}

[1] Daniel Feuermann and Jeffrey M Gordon. High-concentration photovoltaic designs based on miniature parabolic dishes. Solar Energy, 70(5):423-430, 2001.

[2] Cristina Sierra and Alfonso J. Vazquez. High solar energy concentration with a fresnel lens. Journal of Materials Science, 40(6):1339-1343, Mar 2005.

[3] "Technology Roadmap Solar Photovoltaic Energy - 2014 Edition," n.d., 60.

[4] Pavlov M., doi: 10.1109/JPHOTOV.2015.2478057.

[5] Gelegenis, John \& Axaopoulos, Petros \& Misailidis, Stavros \& Giannakidis, George \& Samarakou, Maria \& Bonaros, Bassilios. (2015). Feasibility for the use of Flat Booster Reflectors in Various Photovoltaic Installations. International Journal of Renewable Energy Research. 5. 82-98.

[6] Photovoltaic Geographical Information System (PVGIS). http://re.jrc.ec.europa.eu/pvgis.

[7] Suri, M., Huld, T., Dunlop, E. D., \& Cebecauer, T. (2008). Geographic aspects of photovoltaics in Europe: contribution of the PVGIS website. IEEE Journal of Selected Topics in Applied Earth Observations and Remote Sensing, 1(1), 34-41.

[8] Grover Hughes' class and related class materials on Engineering Astronomy at Sandia National Laboratories, 1985.

[9] Abdel Nour C. et al, Geometrical optimization for a photovoltaic installation equipped with flat reflectors based on plane of array estimations. EPJ Photovolt. (Under review).

[10] Haeffelin, M., Barthès, L., Bock, O., Boitel, C., Bony, S., Bouniol, D., \& Drobinski, P. (2005, February). SIRTA, a ground-based atmospheric observatory for cloud and aerosol research. In Annales Geophysicae (Vol. 23, No. 2, pp. 253275).

[11] Gelegenis J., et al, (2015). Feasibility for the use of Flat Booster Reflectors in Various Photovoltaic Installations. International Journal of Renewable Energy Research.

[12] Abdel Nour C., et al, "Photovoltaic system equipped with flat reflectors: new MPPT model in case of non-uniform illumination on PV modules". ", 35th European PV Solar Energy Conference and Exhibition (Eu-PVSEC), Brussels (Belgium), September 2018. 